\title{
DOES PARITY AFFECT ABDOMINAL ENDURANCE CAUSING LOW BACK PAIN AMONG WOMEN?
}

Khadgi $B^{1 *}$, Karki $A^{1}$, Acharya $R^{1}$

\begin{abstract}
Affiliation
1. Department of physiotherapy, Kathmandu University School of Medical Sciences
\end{abstract}

\section{ARTICLE INFO}

Received : 23 June, 2019
Accepted : 22 December, 2019
Published : 31 December, 2019

(c) Authors retain copyright and grant the journal right of first publication with the work simultaneously licensed under Creative Commons Attribution License CC - BY 4.0 that allows others to share the work with an acknowledgment of the work's authorship and initial publication in this journal.

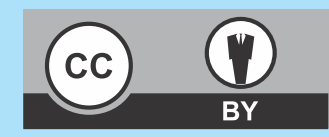

ORA 132

DOI: http://dx.doi.org/10.3126/bjhs.v4i3.27016

\section{* Corresponding Author}

Ms. Bimika Khadgi

Department of Physiotherapy

Dhulikhel Hospital/ Kathmandu University Hospital

Kathmandu University School of Medical Sciences Dhulikhel, Kavre, Nepal

Email ID: bimikhadgi@gmail.com

ORCID ID: https://orcid.org/0000-0002-7324-9419

\section{Citation}

Khadgi B, Karki A, Acharya R. Does Parity Affect Abdominal Endurance Causing Low Back Pain Among Women? BJHS 2019;4 (3)10: 791-795.

\section{ABSTRACT}

\section{Introduction}

Low back pain (LBP) is common worldwide and is leading cause of disability. Abdominal endurance promotes body posture, position, balance, urinary continence, pelvic lignment and low back health. In Nepal, women have high level physical activities and need good endurance to perform those activities. During pregnancy and postpartum, woman's body undergoes remarkable changes up to 1 year resulting in pelvic pain, back pain and incontinence and other associated problems. Transverse abdominus is not as active as before pregnancy resulting in inadequate muscular stabilization in spine. Hence, study intends to measure abdominal endurance and compare among nulliparous, primiparous and multiparous women with association to low back pain.

\section{Objectives}

To compare the abdominal endurance among nulliparous, primiparous and multiparous women and to assess the association of abdominal endurance with LBP.

\section{Methodology}

Non- parous and parous women of 20-30 years with 100 sample size are included to measure abdominal endurance by Pressure Biofeedback Unit and Nordic questionnaire was administered to identify low back pain.

\section{Results}

Mean abdominal endurance found among nulliparous was $3.5 \mathrm{~mm}$ of $\mathrm{Hg}$, primiparous was $3.4 \mathrm{~mm}$ of $\mathrm{Hg}$ and multiparous was $3.2 \mathrm{~mm}$ of $\mathrm{Hg}$. Chi-square test showed $45.5 \%$ nulliparous, $48.5 \%$ primiparous and $52.9 \%$ multiparous women have below average abdominal endurance and $33.3 \%, 57.6 \%$ and $70.6 \%$ nulliparous, primiparous and multiparous women have low back pain(LBP) respectively. The association between LBP and abdominal endurance is 0.155 .

\section{Conclusion}

Abdominal endurance decreases with increasing parity and LBP increases with parity. Further research with large sample size is needed to explore the association between the LBP and abdominal endurance.

\section{KEYWORDS}

Transverse abdominus; parity; low back pain; abdominal endurance. 


\section{INTRODUCTION}

Low back pain (LBP) is the leading cause of years lived with disability in Nepal and elsewhere. Endurance of the abdominal muscles are important in promoting good body posture including position and correct pelvic alignment, body balance and to maintain the continence. ${ }^{2,3}$ Decrease in abdominal endurance can risk to urinary incontinence (UI),pelvic instability and LBP. ${ }^{4}$ According to Global Burden of Disease data, LBP is the number one cause of disability in Nepal; since 2005 the number of years lived with disability due to low back pain in Nepal increased by $16.9 \%$. ${ }^{5}$ LBP leads to difficulties in physical functioning, specifically walking, bending, lifting, doing household chores ultimately decreasing quality of life(QOL). ${ }^{5.7}$ In Nepal $84.3 \%$ women are involved in agriculture and forestry which demands very high work load and burden with both farming and household activity. ${ }^{8}$ The daily activities of the women included in the agriculture as well as the house hold require extreme bending or twisting of the neck and back as well as carrying heavy load. . Lifting up the loads and working mainly on standing and squatting demands activity of the abdominal muscles for which they need to have good abdomin alendurance. ${ }^{9,10}$ Nepalese women continue their household and regular work during their pregnancy and even after delivery. During pregnancy, there is remodeling of connective tissues and increase in the collage nolyticsystem which weakens abdominal muscle and also decreases the abdominals endurance. ${ }^{10}$ There is also hyperlordosis of lumbar spine resulting anterior shift of center of gravity (COG), increasing the anterior pelvic tilt. This increases stress and pain in low back, pelvic and sacroiliac region. ${ }^{6,11} \mathrm{~A}$ woman's body undergoes remarkable changes not only during pregnancy but also during postpartum period. Studies showed that pelvic pain (5 to $20 \%$ ), back pain (30 to $45 \%)$ and UI (29\%) occurs due to decrease in abdominal endurance during postpartum period. ${ }^{11-13}$ This can compromise QOL decreasing participation in physical activities and doing household chores.

The endurance or the activation of the deepest abdominal muscle Transverse Abdominus muscle (TrA), a dynamic muscular corset, assist in postural control and stabilization of the lumbar spine. ${ }^{20-22}$ Over stretching of the abdominal muscles during pregnancy results in adequate muscular stabilization of the lumbar spine causing LBP, pelvic girdle pain(PGP), $\mathrm{UI}$ and also reduces the laxity of $\mathrm{SI}$ joint. ${ }^{14}$ All these factors are responsible for limitation in daily living activities due to physicalin activity and disability and ultimately decreases QOL. Early identification of TrA activity helps in preventing problems and also to know whether abdominal endurance is affected by parity or not. Therefore, this study aims to measure the abdomin alendurance in nulliparous, primiparous and multiparous women and to comprehend the association of abdominal endurance with LBP.

\section{METHODOLOGY}

The Cross sectional study with convenient purposive sampling was done among 100 women and divided them into three groups of nulliparous, primiparous and multiparous with inclusion criteria of female with age 20-30 years with duration of at least 1 year child birth. Women with Spinal or recent abdominal surgery including caesarean birth (1 year duration), pregnant women, women involved in abdominal exercise, and serious pathologies (e.g.lumbar fracture, cancer, infectious diseases of the spine, neurological disorders) were excluded from the study. After official permission received from Dhulikhel Municipality and from Institutional Review Committee data collection was started. The demographic data of participants (nulliparous, primiparous and multiparous) were recorded and screened according to selection criteria 100 women divided in three groups: thirtythree nulliparous and primiparous and whereas multiparous was thirty four. The participants were explained about the purpose, risks and benefits of the study. Verbal and written consent were taken from selected participants prior to data collection.

Pressure Biofeedback Unit (PBU) is a tool that quantitatively measures the activation and endurance of the TrA with excellent psychometric properties. ${ }^{21.23}$ Nordic Musculoskeletal Questionnaire (NMQ) is a screening tool of the musculoskeletal disorders, used as self-administered questionnaires or as interview and is a body part specific questionnaire. ${ }^{19}$ In NMQ, body chart is showed to mark any painful area such as back (upper and lower), neck, hand, elbow, knee and foot. ${ }^{15,27}$

For BMI, inch tape and weighing machine was used by researcher and to measurethe abdominal endurance, Pressure Biofeedback of Chattanooga ISO 13485 Certified Company was used, to measures the fatigue time of the deep abdominal muscles. ${ }^{21}$ The Pressure Bio feedback Unit (PBU) is a simple pressure transducer consisting of a three-chamber: air-filed pressure bag, catheter and a sphygmomanometer gauge. Participants were placed on prone position, arms at side; head fully relaxed in the midline and feet off the plinth for the measurement. The procedures were explained and demonstrated at first. Then the inflatable cell was placed centrally beneath the abdomen between the lower edge at the level of the anterior superior Iliac spines (ASIS) and umbilicus. The subjects were verbally instructed to contract their TrA selectively using an abdominal drawing-in maneuver as "Draw in your abdomen without moving the spine or pelvis" and maintain these contractions for ten seconds (by stopwatch) with normal breathing pattern. Before starting the contraction, the bag was inflated to a 
pressure of $70 \mathrm{mmHg}$ with the valve closed. Participants were instructed to inspire and expire deeply using mainly abdominal wall and participants were asked to relax, then the inflatable bag was adjusted again to $70 \mathrm{mmHg}$. The ability to contract the TrA muscle results in a pressure reduction from 4 to $10 \mathrm{mmHg}$, recorded by pressure gauge of PBU, is known as good contractility of TrA. Contractions with visible co-contractions of other muscles (gluteal, quadriceps or back muscles, tilting of the pelvis or flexing of the spine) with pressure reductions of $0 \mathrm{~mm} \mathrm{Hg}$ or positive values, were not registered. Then subjects were given a new trial. The mean score of three trials were noted. After this Nordic Musculoskeletal Questionnaire (NMQ) was administered by interview method for the LBP and the body chart was shown to mark the painful region.

After data collection, the data were entered in SPSS-16 for further analysis. Participants demographic (age, BMI, gravida, parity, mode of delivery, duration after delivery) represented in form of descriptive statistics. Chi-square test is used for the comparison of abdominal endurance and association with LBP.

\section{RESULT}

The data was collected from the women residing in Dhulikhel community using pressure biofeedback and self-administered questionnaire-Nordic musculoskeletal questionnaire, were analyzed and interpreted. Out of 100 women participants, majority (56\%) were between $25-30$ years and most of them were housewives. Most of the participants are educated. The socio-demographic of the women are shown in Table no 1. The maximum participants had normal delivery with episiotomy. $72 \%$ of the participant's has $1-5$ years birth spacing between last 2 deliveries. The obstetric characteristics are shown in table no 2 . The mean endurance among nulliparous is $3.4760 \mathrm{~mm}$ of $\mathrm{Hg}$, primiparous is $3.3919 \mathrm{~mm}$ of $\mathrm{Hg}$ and multiparous is $3.1829 \mathrm{~mm}$ of $\mathrm{Hg}$ which is shown in table no 3.

Table 1: Characteristics of the participants.
\begin{tabular}{|l|c|c|}
\hline Demographics & Distribution & Percentage \\
\hline \multirow{3}{*}{ Age } & $20-24$ & $44 \%$ \\
\hline \multirow{4}{*}{ Occupation } & $25-30$ & $56 \%$ \\
\cline { 2 - 3 } & Housewife & $38 \%$ \\
\cline { 2 - 3 } & Student & $27 \%$ \\
\cline { 2 - 3 } & Shopkeeper & $17 \%$ \\
\cline { 2 - 3 } & Service & $8 \%$ \\
\hline \multirow{4}{*}{ Education level } & Farmer & $8 \%$ \\
\cline { 2 - 3 } & Tailor & $2 \%$ \\
\cline { 2 - 3 } & Illiterate & $16 \%$ \\
\cline { 2 - 3 } & Upto 5 class & $8 \%$ \\
\cline { 2 - 3 } & $6-10$ class & $8 \%$ \\
\cline { 2 - 3 } & Upto 12 & $31 \%$ \\
\cline { 2 - 3 } & Bachelors & $28 \%$ \\
\cline { 2 - 3 } & Masters & $9 \%$ \\
\hline
\end{tabular}

Table 2: Obstetric characteristics of women

\begin{tabular}{|l|l|c|}
\hline Parity & Nulliparous & $33 \%$ \\
\cline { 2 - 3 } & Primiparous & $33 \%$ \\
\cline { 2 - 3 } & Multiparous & $34 \%$ \\
\hline Mode of delivery & Normal delivery & $29.9 \%$ \\
\cline { 2 - 3 } & $\begin{array}{l}\text { Normal delivery with } \\
\text { episiotomy }\end{array}$ & $38.8 \%$ \\
\cline { 2 - 3 } Birth spacing & c- section & $31.3 \%$ \\
\cline { 2 - 3 } & 1-5 years & $72.2 \%$ \\
\cline { 2 - 3 } & 6-10 year & $22.2 \%$ \\
\cline { 2 - 3 } & More than 10 years & $5.6 \%$ \\
\hline
\end{tabular}

Table 3: Mean abdominal endurance and parity.
\begin{tabular}{|l|c|}
\hline Parity & Parity Mean abdominal endurance \\
\hline Nulliparous & $3.4760 \mathrm{~mm}$ of Hg \\
\hline Primiparous & $3.3919 \mathrm{~mm}$ of Hg \\
\hline Multiparous & $3.1829 \mathrm{~mm}$ of Hg \\
\hline
\end{tabular}

Abdominal endurance among women:

Out of 33 nulliparous, 33primiparous and 34 multiparous women $45.5 \%, 48.5 \%$ and $52.9 \%$ have below average abdominal endurance respectively as shown in below.

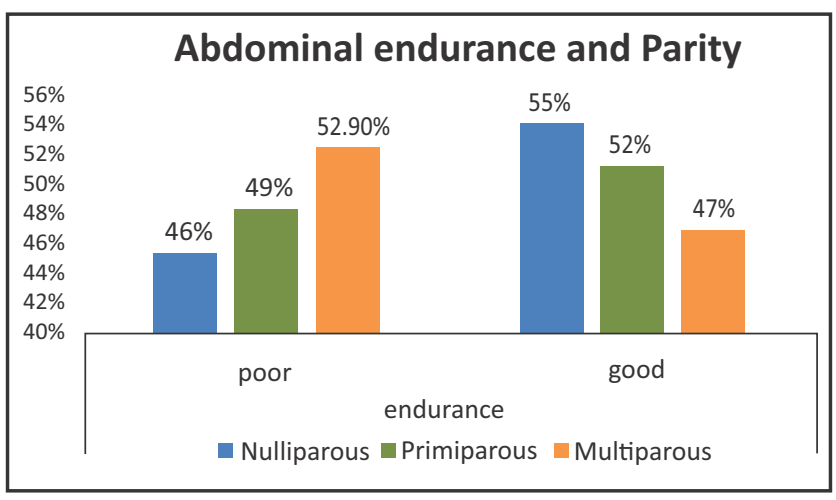

Figure 1: abdominal endurance and parity

Parity and low back pain:

Bar graph 2 showed that nulliparous women 33.3\% $(n=11)$ have LBP, among primiparous women $57.6 \%(n=19)$ have LBP and majority of multiparous $70.6 \%(n=24)$ have LBP.

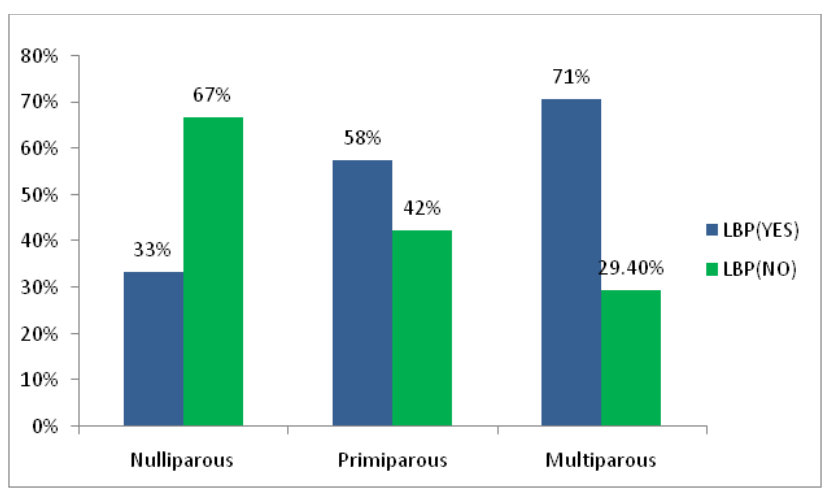

Figure 2: Parity and LBP

Abdominal endurance and low back pain:

Among 49 participants with poor abdominal endurance majority $(n=30)$ have low back pain and among 51 participants with good abdominal endurance majority 
$(n=27)$ doesn't have low back pain. There is significant association between parity and LBP with $p$ value 0.004 but no association between parity and endurance as shown in table no. 4. The association between LBP and abdominal endurance is 0.155 which is not significant as well.

Table 4: Association of Parity with LBP and Abdominal
Endurance
\begin{tabular}{|l|c|c|c|c|c|}
\hline \multirow{2}{*}{ LBP } & Yes & 11 & 18 & 25 & \multirow{3}{*}{0.004} \\
\cline { 2 - 6 } & Nulli & Primi & Multi & \\
\cline { 2 - 6 } & No & 22 & 15 & 9 & \\
\hline Endurance & Good & 18 & 18 & 14 & \multirow{2}{*}{0.448} \\
\cline { 2 - 5 } & Poor & 15 & 15 & 20 & \\
\hline
\end{tabular}

\section{DISCUSSION}

The objective of this study is to measure the abdominal endurance among nulliparous, primiparous and multiparous women and also to see the association between abdominal endurance and LBP with parity. This study strongly supports that there will be change in abdominal endurance among nulliparous, primiparous and multiparous women. Abdominal muscle function deficit is present during pregnancy due to more stretch of abdominals and as parity increases its function will be reduced more. ${ }^{12}$ For normal vaginal delivery with or without episiotomy pelvic floor muscle function is decreased according to the study conducted by Hilde $\mathrm{G}$ et al, 2013. ${ }^{28}$ Abdominal endurance or the activity of transverse abdominus is also decreased among the women who have decreased pelvic floor muscle function according to the study done by Stephanie J. Madill et al, 2006. ${ }^{29}$ This study showed similar result done by Liaw $L$ et al that abdominal endurance decreases with increase in parity. ${ }^{11}$ Multiparous has low abdominal endurance than primiparous and primiparous has low abdominal endurance than nulliparous. However, there are limited studies done specifically examining the abdominal endurance after 1 year of delivery but we found evidence more on that abdominal function decreases up to 6 month postpartum than nulliparous females. ${ }^{12}$ As Nepalese women have high work load and their household activity requires extreme bending or twisting of the neck and back with lifting loads, their work position mainly is standing and squatting which require good abdominal endurance. ${ }^{9,10}$ They have to continue these work during their pregnancy and even after delivery. Abdominal muscle function deficit is present during pregnancy due to more stretch of abdominals. This might be the reason that abdominal endurance decreases with parity. Low back pain is one of the common problem which is considered as normal during pregnancy with prevalence of $20 \%$ to $84 \%{ }^{6}$ The incidence of back pain in postpartum women has also been quoted to be between $30 \%$ and $45 \%$ after 2 years and $20 \%$ in 6 years. ${ }^{26}$ Our study supported the result published by The in-Nissenbaum et al showing low back pain is present during postpartum period. ${ }^{25}$ It may be due to the more decrease in abdominal function or endurance with increase with number of pregnancy. With less abdominal function combined with more workload or household chores might be the reason behind the increased low back pain. Multiparity displayed an increased risk of musculoskeletal conditions, due to the repeated weight strain, stretching of abdominals decreasing in abdominal function, endurance and strength. Additionally, each new child in a family increases the workload in early motherhood like repeated lifting causing back pain. ${ }^{27}$ In this study participant who complaint back pain were asked about three difficult activities with household and they complained mainly washing clothes as it requires bending forward and also during prolonged standing and sitting aggravates pain. Washing clothes and sitting requires squatting position which stretches the pelvic floor muscles causing its weakness. This results in less activation of abdominals causing more back pain. ${ }^{26}$ More back pain might be because these activities needs more function of back stabilizers. ${ }^{27}$ Low back pain is the number one cause of disability in Nepal and the burden is increasing. ${ }^{1}$ In this study we couldn't find the association of abdominal endurance with low back pain, though participants complained of low back pain with increasing parity and they had less abdominal endurance. Reason for this may be the small sample size in the study. Research done in rural Nepal reported $28 \%$ pelvic organ prolapse among adolescent women $20-29$ age group. ${ }^{17}$ The mean age of the women in our study is also $25-30$ years. LBP was common among nulliparous with $33 \%$ and primiparous with $57 \%$ and multiparous with $70 \%$. This shows the disability is increasing as the parity is increasing. LBP could be one the symptom for the POP among the women which has to be identified early for the betterment of QOL. ${ }^{16}$ Habituation of LBP with increase in time can also be another reason behind it. Therefore, our study showed that abdominal endurance decreases along with increase in parity and low back pain also increases along with parity but LBP was not associated with parity in our study.

\section{CONCLUSION}

This study concluded that abdominal endurance decreases with increase in parity. We also found that LBP was more common in multiparous women as compared to primiparous and nulliparous women. This study showed that there is no association between abdominal endurance and low back pain but the future study with large population will give more detail picture about this.

\section{RECOMMENDATIONS}

Based on the results and finding of study we would like to recommend for the following:

- Socio cultural barriers affecting abdominal endurance should be assessed in future studies.

- Initiate proper postpartum rehabilitation protocol with respect to socio cultural need of Nepalese women

- Abdominal strengthening and endurance exercises should be incorporated during pregnancy and postpartum. 


\section{LIMITATION OF THE STUDY}

These findings of the study could not be generalized due to its small sample size.

\section{ACKNOWLEDGEMENTS}

We would like to acknowledge all participants for their support without them; this study would not have been possible.

\section{CONFLICT OF INTEREST}

The authors declare no conflict of interest.

\section{FINANCIAL DISCLOSURE}

None

\section{REFERENCES}

1. Sharma S, Traeger AC, Mishra SR, Sharma S, Maher CG. Delivering the right care to people with low back pain in low-and middle-income countries: the case of Nepal. Journal of global health. 2019 Jun;9(1).doi: 10.7189/jogh.09.010304

2. Kovácsné VB, Szilágyi B, Makai A, Koller Á, Járomi M. Improvement of lumbal motor control and trunkmuscle conditions with a novel low back pain prevention exercise program. Orvosihetilap. 2017 Jan;158(2):58-66. doi: 10.1556/ 650.2017.30640

3. Moffroid MT. Endurance of trunk muscles in persons with chronic low back pain: assessment, performance, training. Journal of rehabilitation research and development. 1997 Oct 1;34:440-7. PMID: 9323647

4. Institute for Health Metrics and Evaluation. What health problems cause the most disability? 2018. Available: http://www.healthdata.org/nepal. Accessed: 14 June 2018.

5. Acharry N, Kutty RK. Abdominal exercise with bracing, a therapeutic efficacy in reducing diastasis-recti among postpartal females. Int J Physiother Res. 2015;3 (2):999-1005. doi: 10.16965/ijpr.2015.122

6. Noon ML, Hoch AZ. Challenges of the pregnant athlete and low back pain. Current sports medicine reports. 2012 Jan 1;11(1):43-8. doi:10.1249/JSR.0b013e31824330b6

7. Tajiri K, Huo M, Maruyama H. Effects of co-contraction of both transverse abdominal muscle and pelvic floor muscle exercises for stress urinary incontinence: a randomized controlled trial. Journal of physical therapy science. 2014;26(8): 1161-3. doi: 10.1589/jpts.26.1161

8. Tamang S, Paudel KP, Shrestha KK. Feminization of agriculture and its implications for food security in rural Nepal. Journal of Forest and Livelihood. 2014 Oct;12(1):20-32.

9. Walker GJ, Gunasekera P. Pelvic organ prolapse and incontinence in developing countries: review of prevalence and risk factors. International urogynecology journal. 2011 Feb 1;22(2):127-35. DOI: 10.1007/s00192-010-1215-0

10. Borg-Stein J, Dugan SA. Musculoskeletal disorders of pregnancy, delivery and postpartum. Physical medicine and rehabilitation clinics of North America. 2007 Aug 1;18(3):459-76. DOI: 10.1016/j.pmr.2007.05.005

11. Liaw L, Hsu MJ, Liao CF, Liu MF, Hsu AT. The relationships between inter-rect distance measured by ultrasound imaging and abdominal muscle function in postpartum women: a 6-month follow-up study. journal of orthopaedic\& sports physical therapy. 2011 Jun;41(6):435-43. DOI: 10.2519/jospt.2011.3507

12. Gutke A, Östgaard HC, Öberg B. Association between muscle function and low back pain in relation to pregnancy. Journal of rehabilitation medicine. $2008 \mathrm{Apr}$ 5;40(4):304-11. DOI: 10.2340/16501977-0170

13. Potthoff T, de Bruin ED, Rosser S, Humphreys BK, Wirth B. A systematic review on quantifiable physical risk factors for non-specific adolescent low back pain Journal of pediatric rehabilitation medicine. 2018 Jan 1;11(2):79-94. DOI: 10.3233/PRM-170526

14. Kluge J, Hall D, Louw Q, Theron G, Grové D. Specific exercises to treat pregnancy-related low back pain in a South African population. International Journal of Gynecology \& Obstetrics. 2011 Jun;113(3):187-91. DOI: 10.1016/j.ijgo.2010.10.030

15. Crawford JO. The Nordic musculoskeletal questionnaire. Occupational medicine. 2007 Jun 1;57(4):300-1. https://doi.org/10.1093/occmed/kgm036

16. Thapa B, Rana G, Gurung S. Contributing factors of utero-vaginal prolapse among women attending in Bharatpur hospital. Journal of Chitwan Medical College. 2014;4(3):38-42. DOI: https://doi.org/10.3126/jcmc.v4i3.11939
17. Gurung G, Rana A, Amatya A, Bista KD, Joshi AB, Sayami J. Pelvic organ prolapse in rural Nepalese women of reproductive age groups: What makes it so common? Nepal Journal of Obstetrics and Gynaecology. 2007;2(2):3541.DOI: https:// doi.org/10.3126/njog.v2i2.1453

18. Gilleard WL, Brown JM. Structure and function of the abdominal muscles in primigravid subjects during pregnancy and the immediate postbirth period. Physical therapy. 1996 Jul 1;76(7):750-62. PMID:8677279

19. Kuorinka I, Jonsson B, Kilbom A, Vinterberg H, Biering-Sørensen F, Andersson G, $J \emptyset$ rgensen K. Standardised Nordic questionnaires for the analysis of musculoskeletal symptoms. Applied ergonomics. 1987 Sep 1;18(3):233-7. https://doi.org/10.1016/0003-6870(87)90010-X

20. El-Mekawy HS, Eldeeb AM, El-Lythy MA, El-Begawy AF. Effect of abdominal exercises versus abdominal supporting belt on post-partum abdominal efficiency and rectus separation. InProceedings of World Academy of Science, Engineering and Technology 2013 Jan 1 (No. 73, p. 742). (WASET). ISNI:0000000091950263

21. Lima PO, Oliveira RR, MouraFilho AG, Raposo MC, Costa LO, Laurentino GE. Concurrent validity of the pressure biofeedback unit and surface electromyography in measuring transversusabdominis muscle activity in patients with chronic nonspecific low back pain. Brazilian Journal of Physical Therapy. 2012 Oct;16(5):389-95. PMID: 22832703

22. Von Garnier K, Köveker K, Rackwitz B, Kober U, Wilke S, Ewert T, Stucki G. Reliability of a test measuring transversusabdominis muscle recruitment with a pressure biofeedback unit. Physiotherapy. 2009 Mar 1;95(1):8-14. DOI: 10.1016/j.physio.2008.10.003

23. de Paula Lima PO, de Oliveira RR, de MouraFilho AG, Raposo MC, Costa LO, Laurentino GE. Reproducibility of the pressure biofeedback unit in measuring transversusabdominis muscle activity in patients with chronic nonspecific low back pain. Journal of bodywork and movement therapies. 2012 Apr 1;16(2):2517. DOI: $10.1016 / \mathrm{j} . j b m t .2011 .06 .003$

24. Kahraman T, Genç A, Göz E. The Nordic Musculoskeletal Questionnaire: crosscultural adaptation into Turkish assessing its psychometric properties. Disability and rehabilitation. 2016 Oct 8;38(21):2153-60. DOI: 10.3109/09638288. 2015.1114034

25. Thein-Nissenbaum JM, Thompson EF, Chumanov ES, Heiderscheit B. Low back and hip pain in a postpartum runner: applying ultrasound imaging and running analysis. journal of orthopaedic\& sports physical therapy. $2012 \mathrm{Jul} ; 42$ (7):615-24. DOI: 10.2519/jospt.2012.3941

26. Bliddal M, Pottegård A, Kirkegaard H, Olsen J, Jørgensen JS, Sørensen TI, Dreyer L, Nohr EA. Association of Pre-Pregnancy Body Mass Index, Pregnancy-Related Weight Changes, and Parity With the Risk of Developing Degenerative Musculoskeletal Conditions. Arthritis \& Rheumatology. 2016 May;68(5):115664. DOI: $10.1002 / a r t .39565$

27. Pereira LC, Botelho S, Marques J, Amorim CF, Lanza AH, Palma P, Riccetto C. Are transversusabdominis/oblique internal and pelvic floor muscles coactivated during pregnancy and postpartum?.Neurourology and Urodynamics. 2013 Jun;32(5):416-9. DOI: 10.1002/nau.22315

28. Hilde G, Stær-Jensen J, Siafarikas F, Engh ME, Brækken IH, Bø K. Impact of childbirth and mode of delivery on vaginal resting pressure and on pelvic floor muscle strength and endurance. American journal of obstetrics and gynecology. 2013 Jan 1;208(1):50-e1. DOI: 10.1016/j.ajog.2012.10.878

29. Madill SJ, McLean L. Relationship between abdominal and pelvic floor muscle activation and intravaginal pressure during pelvic floor muscle contractions in healthy continent women. Neurourology and Urodynamics: Official Journal of the International Continence Society. 2006;25(7):722-30. DOI: 10.1002/ nau. 20285 